\title{
A atualidade do conceito de gerações de Karl Mannheim
}

Wivian Weller ${ }^{1}$

Resumo: O conceito de gerações vem sendo retomado nas análises sociológicas que apontam não somente para as diferenças de classe, mas também para as desigualdades de gênero, étnico-raciais, culturais e geracionais. No entanto, "gerações" aparece como uma espécie de conceito guarda-chuva ou como categoria pouco teorizada. Embora o conceito de gerações de Mannheim represente, para muitos autores, a mais completa tentativa de explicação do tema, o mesmo tem sido, muitas vezes, citado por se tratar de um "clássico": as potencialidades de análise do conceito proposto pelo autor ainda são muitas. O presente artigo apresenta, por um lado, uma reconstrução deste "famoso" ensaio que até hoje não chegou a ser integralmente traduzido e publicado no Brasil e, por outro, discute a atualidade e pertinência do artigo escrito por Mannheim em 1928 para os estudos contemporâneos sobre gerações e suas interfaces com outros campos.

Palavras chave: gerações, sociologia do conhecimento, Karl Mannheim.

1. Considerações iniciais:

As traduções de "O problema das gerações" de Mannheim

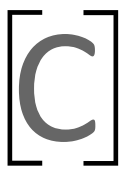

onta-se atualmente com duas versões do ensaio em língua portuguesa, ambas realizadas a partir da versão inglesa publicada em 1952 em uma coletânea com textos de Karl Mannheim - Essays on the sociology of knowledge - organizada por Paul Kecskemeti (Routledge \& Kegan Paul: 276-322). Ao que me consta, a primeira versão em português foi publicada no Brasil em 1982 em uma coletânea de textos organizada por Marialice M. Foracchi e que integra a coleção "Grandes Cientistas Sociais" da editora Ática. Nesta edição, o artigo foi reduzido em cerca de 20 páginas em relação ao texto original e à versão inglesa utilizada para a tradução: excluiu-se o capítulo introdutório (pp. 276-286 da versão inglesa) assim como o último capítulo, que, no original, é sinalizado apenas com o número 7 e na versão em inglês recebe o subtítulo The generation in relation to other
1. Doutora em sociologia pela Universidade Livre de Berlim, Alemanha. Professora adjunta da Faculdade de Educação da Universidade de Brasília e bolsista de produtividade em pesquisa do CNPq. Email:

wivian@unb.br 
2. $O$ artigo foi publicado em um dossiê organizado em homenagem aos 100 anos de nascimento de Karl Mannheim (19831947). Disponível para download em: http://www.reis. cis.es/REISWeb/PDF/ REIS_062_12.pdf. formative factors in history (pp. 312-322). Também foram suprimidas algumas notas de rodapé nas versões em inglês e português, e ao leitor brasileiro, tampouco foi oferecida a lista bibliográfica utilizada por Mannheim na elaboração de seu artigo e que compreende 33 títulos.

A segunda versão disponível em português foi publicada em Portugal pela RES editora no segundo volume da coletânea de textos de Karl Mannheim intitulada "Sociologia do conhecimento". Essa tradução apresenta a mesma estrutura da versão inglesa, ou seja, traz o texto na íntegra (cf. pp. 115-176). Ambas as versões possuem algumas incompreensões ou distorções do texto original, sobretudo no que diz respeito à tradução de alguns conceitos empregados por Mannheim. Esses problemas são resultantes da falta de rigor e de cuidado por parte dos tradutores da versão inglesa. Nesse sentido, se quisermos obter uma leitura mais próxima do texto em alemão e resgatar o sentido original de alguns termos que os tradutores da versão inglesa não souberam captar, é necessário recorrermos à versão espanhola do artigo publicado na Revista Española de Investigaciones Sociológicas (REIS), em 1993.2

\section{O problema das gerações na perspectiva de Karl Mannheim}

Embora o conceito de gerações de Karl Mannheim represente, para muitos, a mais completa tentativa de explicação do tema (Domingues, 2002: 69), o mesmo tem sido muitas vezes citado por se tratar de um "clássico" ou ainda para apontar as incongruências desse ensaio em relação ao conjunto da obra de Mannheim (Matthes, 1985). Schäffer (2003: 56) critica ainda o recorte realizado por alguns autores que se apropriam de partes do artigo - sobretudo a subdivisão do conceito de geração de Mannheim em Generationslagerung (posição geracional), Generationszusammenhang (conexão geracional) e Generationseinheit (unidade geracional) -, que mesmo representando parte importante do artigo, só faz sentido quando analisada no conjunto e a partir das leituras que levaram Mannheim a essa "conceituação fina" (Forquin, 2003) do conceito de gerações. Nesse sentido, o presente artigo foi elaborado com o objetivo de resgatar a relevância do conceito mannheimiano para as pesquisas sociológicas sobre gerações, bem como suas interfaces com outros campos. 
3. Esse tópico compreende a primeira parte do ensaio que não se encontra publicada no Brasil. Para maiores detalhes, cf. a versão inglesa ( $p p$. 276-286) ou espanhola (pp. 147, 193204).

Parece que aqui a explicação do tempo do progresso e a presença de forças, tanto conservadoras como reformistas, é deduzida de forma imediata do fator biológico (p. 511 - trad. nossa).

Os positivistas estavam tentando esboçar uma lei geral para o ritmo da história a partir do determinante biológico da duração limitada da vida de um indivíduo, do fator idade e de suas etapas. Segundo Mannheim, para essa corrente do pensamento:

A meta é compreender imediatamente as mudanças formais das correntes espirituais e sociais a partir da esfera biológica, apreender a forma de progresso da espécie humana com base nos elementos vitalícios. Nisto simplifica-se tudo o que é possível: a psicologia esquemática trata de estabelecer continuamente a velhice como o elemento conservador e a juventude é vista unicamente em seu aspecto tempestuoso. A história das ciências humanas aparece nessa caracterização como se houvessem sido estudadas apenas as tabelas cronológicas históricas. Após essa simplificação, a dificuldade do problema parece residir apenas sobre este aspecto: encontrar o tempo médio no qual uma geração anterior é substituída por uma nova na vida pública e, sobretudo, encontrar o ponto de início natural no qual se procede um corte na história, a partir do qual se deve começar a contar. A duração da geração é determinada de forma diversa a cada momento. Alguns fixam a duração do efeito de geração em 15 anos (por exemplo, Dromel); mas a maioria em 30, considerando que os primeiros 30 anos são os anos de formação, quando, normalmen- 
4. Assim escreve Mannheim: "Não existe melhor comprovação para a tese de que a forma de colocar as questões bem como o modo de colocar as qustões variam de acordo com o país, a época e as vontades políticas dominan-

tes do que a confrontação das soluções dadas a esses problemas nos diferentes países $c p$, suas correntes

dominantes específicas" (p. 514). te, se inicia o processo individual criativo do indivíduo; aos 60 o ser humano deixa a vida pública (pp. 511s).

Mannheim não esconde sua preferência pela abordagem histórico-romântica alemã e destaca ainda que este é um exemplo bastante claro de como a forma de se colocar uma questão pode variar de país para país, assim como de uma época para outra. ${ }^{4}$ Ao invés de associar as gerações a um conceito de tempo externalizado e mecanicista, pautado por um princípio de linearidade, o pensamento histórico-romântico alemão se esforça por buscar no problema geracional uma contraproposta diante da linearidade do fluxo temporal da história:

O problema geracional se torna, dessa forma, um problema de existência de um tempo interior não mensurável e que só pode ser apreendido qualitativamente,

ou seja, esse tempo interior só pode ser apreendido subjetivamente e não objetivamente (p. 516). Mannheim toma aqui a Dilthey como referência e destaca dois aspectos inovadores no pensamento do mesmo:

ㄱ A contraposição entre a mensuração quantitativa e a compreensão exclusivamente qualitativa do tempo interior de vivência (erfassbarer innerer Erlebniszeit);

$\square \quad$ O fato de que não é somente a sucessão de uma geração que cobra um sentido mais profundo do que o meramente cronológico, mas também o fenômeno da "contemporaneidade" ou "simultaneidade" (Gleichzeitigkeit).

Mannheim incorpora sobretudo o aspecto da "Gleichzeitigkeit" elaborado por Dilthey e destaca que:

Indivíduos que crescem como contemporâneos experimentam nos anos de maior disposição à receptividade, mas também posteriormente, as mesmas influências condutoras tanto da cultura intelectual que os impressiona como da situação político-social. Eles constituem uma geração, uma contemporaneidade, porque essas influências são homogêneas. Justamente por essa mudança - de que a contemporaneidade não significa uma data cronológica no histórico da humanidade mas uma similaridade de influências existentes -, a questão colocada escapa de um plano que tendia a 
converter-se em uma aritmética mística, ao domínio da simples compreensão da temporalidade interior que pode ser percebida (pp. 516s).

Essa noção de vínculo geracional como fruto das experiências vividas na contemporaneidade inspirada no conceito qualitativo de tempo de Dilthey, será elaborada de forma ainda mais radical quando Mannheim recorre à expressão cunhada por Pinder (um historiador da arte) de "não contemporaneidade dos contemporâneos" (Ungleichzeitigkeit des Gleichzeitigen) ou "não simultaneidade do simultâneo" como Domingues preferiu traduzir (2002: 70). Com isso Mannheim chama a atenção para o fato de que diferentes grupos etários vivenciam tempos interiores diferentes em um mesmo período cronológico:

Cada um vive com gente da mesma idade e de idades distintas em uma plenitude de possibilidades contemporâneas. Para cada um o mesmo tempo é um tempo distinto, quer dizer, uma época distinta de si mesmo, que é partilhada com seus coetâneos (Pinder, p. 21 apud Mannheim p. 517).

Outra questão que Mannheim irá trabalhar a partir ideias de Wilhelm Pinder - que publicou em 1926 o livro O problema das gerações na história da arte europeia (Das Problem der Generationen in der Kunstgeschichte Europas) -, diz respeito ao problema da "enteléquia" de uma mesma geração. ${ }^{5}$ SemeIhante ao teorema aplicado por Pinder às mudanças nas gerações de artistas ou às mudanças de cada época na história da arte, Mannheim percebe nas gerações político-sociais um princípio formativo, um dispositivo uniforme que impulsiona e que passa a ser definido pelo termo filosófico de "enteléquia" (cf. Zinnecker, 2002: 74). A enteléquia de uma geração representa a expressão do sentimento genuíno do significado da vida e do mundo, de seus objetivos internos ou de suas "metas íntimas" (cf. Mannheim, 1993: 201/518) que estão relacionadas ao "espírito do tempo" (Zeitgeist) de uma determinada época ou ainda à sua desconstrução, uma vez que várias gerações estão trabalhando simultaneamente na formação do que viria a ser o "espírito do tempo" (cf. Schäffer, 2003: 58s).

Nesse sentido, tanto a noção de "não contemporaneidade dos contemporâneos" como a "enteléquia geracional" constituem categorias centrais a partir das quais o autor irá desenvolver sua análise sociológica sobre o problema das gerações.
5. Na filosofia (Zinnecker, 2002: 74), o conceito de enteléquia foi utilizado para definir "uma substância, uma habilidade ou uma força direcionada com exatidão que regula ou provoca o desenvolvimento posterior do organismo". 


\section{O problema sociológico das gerações}

Mannheim inicia a segunda parte de seu ensaio criticando a falta de unidade na análise do problema das gerações, de pesquisas consistentes sobre o tema e a prevalência de uma "perspectiva estática" nas pesquisas sociológicas sobre grupos humanos, para, em seguida, apresentar alguns conhecimentos relativos ao fenômeno das gerações (pp. 522-524).

Ao analisar a especificidade do convívio dos indivíduos interligados pela unidade geracional (Generationseinheit), o autor chama a atenção para o fato de a unidade de uma geração não consistir em uma adesão voltada para a criação de grupos concretos, preocupados em constituir uma coesão social, ainda que, ocasionalmente, algumas unidades geracionais possam vir a constituir grupos concretos, tais como os movimentos juvenis, entre os quais poderíamos citar o movimento estudantil de 1968. Mas à parte desses casos específicos, nos quais a conexão geracional ( $G e$ nerationszusammenhang) pode levar à formação de um grupo concreto, Mannheim destaca ser ela uma mera conexão, ou seja, casualmente os indivíduos pertencem a ela, mas não se percebem como um grupo concreto (p. 524).

Para Schäffer (op. cit.: 59) a pergunta que se coloca então é a seguinte: qual é a especificidade da "enteléquia geracional" - da expressão de seu sentimento genuíno sobre a vida e o mundo - se a mesma não está associada a um grupo concreto? Se não é a proximidade de um grupo (família, amigos etc.) nem a estrutura de uma organização, quais elementos produziriam esse vínculo geracional? Mannheim responde a essas questões recorrendo a uma categoria social a princípio distinta, mas que apresenta semelhanças com a conexão geracional: a Klassenlage ou a situação de classe. Essa posição (Lagerung) se fundamenta pela presença de um ritmo biológico na existência humana (menschliches Dasein) e apresenta semelhanças com a "situação de classe", na qual as condições socioeconômicas constituem uma base comum:

A situação de classe e a situação geracional (o pertencimento mútuo a anos de nascimento próximos) tem em comum - como consequência de uma posição específica ocupada pelos indivíduos por ela atingidos no espaço de vida sócio-histórico -, a limitação desses indivíduos a um determinado campo de ação e de acontecimentos possíveis, produzindo, dessa forma, uma forma específica de viver e 
de pensar, uma forma específica de intervenção no processo histórico (p. 528).

No entanto, Mannheim chama a atenção para o fato de que o pertencimento a uma geração não pode ser deduzido imediatamente das estruturas biológicas: "O problema sociológico das gerações começa somente onde a relevância sociológica desses dados prévios forem realçadas". (ibidem). A situação de classe e a situação geracional apresentam aspectos similares devido à posição específica ocupada pelos indivíduos no âmbito sócio-histórico. Mas essa posição gera uma modalidade específica do viver e do pensar, da forma como os membros interferem no processo histórico, ou seja: uma tendência inerente a cada posição e que só pode ser determinada a partir da própria posição (ibidem).

\subsection{Características básicas da posição geracional}

A noção de situação geracional é ampliada por meio de um exercício analítico, no qual o autor aponta cinco aspectos que distinguem uma sociedade marcada por mudanças geracionais, tal como as sociedades em que vivemos, de uma sociedade utópica e imaginária:

1. a constante irrupção de novos portadores de cultura;

2. a saída constante dos antigos portadores de cultura;

3. a limitação temporal da participação de uma conexão geracional no processo histórico;

4. a necessidade de transmissão constante dos bens culturais acumulados;

5. o caráter contínuo das mudanças geracionais (p. 530).

Esses elementos caracterizam as gerações como processos dinâmicos e interativos e apresentam características relevantes da teoria mannheimiana sobre as gerações (cf. Schäffer 2003: 60-63).

A constante irrupção de novos portadores de cultura é vista pelo autor como um fenômeno relevante para a vida social, pois são eles os responsáveis pela vitalidade e dinamicidade das sociedades. Embora a sucessão de gerações implique em perdas de bem culturais acumulados, Mannheim chama a atenção para os aspectos práticos dessas mudanças:

A entrada de novas pessoas obstrui os bens constantemente acumulados, mas também produz inconscientemente nova seleção e 
revisão no campo do que está disponível; nos ensina a esquecer o que já não é útil e a desejar o que ainda não foi conquistado ( $p$. 532).

A saída dos antigos portadores de cultura também é positiva na medida em que suscita a memória ou a recordação social, tão importante quanto o esquecimento daquilo que deixou de ser significativo ou necessário. Em relação à memória, Mannheim destaca duas modalidades através das quais as vivências passadas se fazem presentes. Por um lado, "como modelos conscientes", orientadores das ações e condutas dos indivíduos em sociedade; por outro, de forma "inconscientemente comprimida", "intensiva" e "virtual", ou seja: como uma espécie de ferramenta condensadora de todas essas experiências, perceptíveis nas reações trazidas à tona através da recordação dessas experiências (por exemplo: a sentimentalidade). Essa segunda modalidade de memória das vivências passadas remete a um aspecto importante da concepção sobre gerações de Mannheim, no qual o autor ressalta o conhecimento implícito acumulado, elaborando assim uma definição não biológica da velhice e das diferenças entre as velhas e novas gerações:

Alguém é velho principalmente pelo fato de viver em um contexto de experiências específicas, autoadquiridas e pré-formativas, através das quais cada nova experiência é, até certo ponto, classificada de antemão quanto à sua forma e localização. Em contraposição, na nova vida as forças configuradoras estão se constituindo, as intenções primárias e a forte impressão de novas situações ainda precisam ser processadas (p. 534).

O terceiro aspecto relativo à limitação temporal da participação de uma conexão geracional no processo histórico analisa as características geradoras da posição geracional daqueles nascidos em um mesmo tempo cronológico. De acordo com Mannheim, não basta haver nascido em uma mesma época, ser jovem, adulto ou velho nesse período. O que caracteriza uma posição comum daqueles nascidos em um mesmo tempo cronológico é a potencialidade ou possibilidade de presenciar os mesmos acontecimentos, de vivenciar experiências semelhantes, mas, sobretudo, de processar esses acontecimentos ou experiências de forma semelhante. Poderíamos argumentar que os modernos meios de comunicação ampliaram as possibilidades de participação de jovens residentes em continentes distintos em um conjunto de acontecimentos e experiências seme- 
Ihantes colocando-os em uma mesma posição geracional. No entanto, a identificação geracional comum implica em formas semelhantes de ordenação e estratificação dessas experiências.

Ao discutir a necessidade de transmissão constante dos bens culturais acumulados, Mannheim destaca o papel e o desafio das gerações mais velhas em relação às mais novas assim como das instituições de ensino:

Uma educação e um ensino adequados (no sentido da transmissão completa dos centros de vivência necessários para o conhecimento ativo) tornam-se difíceis, uma vez que a problemática vivencial da juventude está voltada para adversários diferentes dos de seus professores (p. 540).

Em outras palavras, as dificuldades existentes entre professores e alunos estão relacionadas às orientações ou visões de mundo distintas de cada geração, como se "os sedimentos mais profundos não pudessem ser desestabilizados" (p. 540). A superação dessa tensão implica em uma interação e troca de papéis: "não é só o professor que educa o aluno, também o aluno educa o professor. As gerações estão em constante interação" (idem).

Com base nesse último exemplo relativo a interação necessária entre aqueles que ensinam e os que aprendem, Mannheim se opõe à ideia de uma suposta dicotomia existente entre as velhas e as novas gerações e destaca o caráter contínuo das mudanças geracionais assim como o papel ocupado pelas "gerações intermediárias" nesse processo:

No processo desse equilíbrio retroativo não são as gerações mais velhas e as mais jovens que se enfrentam, mas as que estão próximas às "gerações intermediárias". São estas que primeiramente exercem influência uma sobre a outra (p. 540).

Para Schäffer (op. cit.), esse último aspecto remete a uma segunda questão central da teoria mannheimiana sobre as gerações: por um lado, destaca o conhecimento implícito acumulado e transmitido de geração para geração com suas devidas releituras e reinterpretações; por outro, aponta para a necessidade de compreensão do problema das gerações como um processo dinâmico. Nesse sentido, Mannheim se aproxima da ideia simmeliana de interação, ou seja, da complexa interação existente entre distintos fatores constitutivos de gerações. 


\subsection{Posição geracional, conexão geracional e unidade geracional}

6. Optamos pela tradução realizada para o espanhol e que define Generationslagerung como posição geracional. Entre outras traduções, encontramos as seguintes: "status de geração" (Editora Ática), "locais geracionais" (Domingues, 2002) "situações de geração" (Forquin, 2003).

\section{A tradução} Generationszusammenhang como conexão geracional (realizada na versão espanhola do artigo) também nos pareceu mais próxima do original, embora a palavra

Zusammenhang também remeta à idéia de contexto. Entre outras traduções, encontramos as seguintes: "geração enquanto realidade" (Editora Ática), "geração como realidade" (RÉS), "gerações como conjuntos de relação" (Domingues, 2002) e "conjuntos de geração" (Forquin, 2003).
A divisão do conceito de gerações e sua especificação progressiva em torno das três definições acima citadas, representam a parte mais conhecida e citada do artigo de Mannheim, ainda que as traduções realizadas para o português remetem a interpretações distintas, sobretudo dos termos posição geracional (Generationslagerung) ${ }^{6}$ e conexão geracional (Generationszusammenhang $)^{7}$.

O que define a posição geracional não é um estoque de experiências comuns acumuladas de fato por um grupo de indivíduos, mas a possibilidade ou "potencialidade" de poder vir a adquiri-las. Ou seja: na noção de Lagerung está implícita a ideia na qual as condições para a vivência de um conjunto de experiências comuns já estão dadas. Se os indivíduos irão "despertar" essa potencialidade imanente é um aspecto, que, dependerá, por sua vez, de outros fatores sociais:

A posição só detém possibilidades potenciais, que podem vir à tona, ser reprimidas ou surgir com um efeito modificado, quando sedimentadas em outras forças sociais influentes (p. 542).

Já a conexão geracional apresenta características mais determinantes do que a posição geracional. Ela pressupõe um vínculo concreto, algo que vai além da simples presença circunscrita a uma determinada unidade temporal e histórico-social. Esse vínculo concreto Mannheim - em alusão a Heidegger - define como uma participação no destino comum dessa unidade histórico-social:

Uma conexão geracional se constitui através da participação dos indivíduos que pertencem à mesma posição geracional, em um destino coletivo comum assim como da partilha de conteúdos que estão relacionados de alguma forma (p. 547).

Para a conexão geracional, não basta participar apenas "potencialmente" de uma comunidade constituída em torno de experiências comuns: é preciso estabelecer um vínculo de participação em uma prática coletiva, seja ela concreta ou virtual. Mannheim recorre aqui à fenomenologia social para analisar o convívio específico (Miteinaderseins) e os vínculos existentes entre os indivíduos pertencentes a uma mesma conexão geracional (cf. Schäffer, 2003: 63s). Nesse sentido, a crítica de que Mannheim 
estaria realizando somente uma transposição da análise de classe para a análise sociológica das gerações (Matthes, 1985) não seria procedente segundo Schäffer (op. cit.).

Existiria então uma conexão geracional unificada? Poderíamos responder positivamente, mas Mannheim segue argumentando sobre a necessidade de definir melhor os termos. Para o autor tanto a juventude românticoconservadora, como a juventude liberal-racionalista, pertencem à mesma conexão geracional, mas estão vinculadas a ela por unidades geracionais (Generationseinheiten) distintas:

Estas [unidades geracionais] se caracterizam não só pela livre participação de diferentes indivíduos em vivências coletivas, que, no entanto, adquirem para si o caráter de acontecimentos distintos, mas pela reação homogênea; num sentido mais próximo, pela vibração e criação uniforme daqueles indivíduos que estão vinculados por uma conexão geracional específica (p. 547).

As unidades de geração desenvolvem perspectivas, reações e posições políticas diferentes em relação a um mesmo problema dado. O nascimento em um contexto social idêntico, mas em um período específico, faz surgirem diversidades nas ações dos sujeitos. Uma outra característica é a adoção ou criação de estilos de vida distintos pelos indivíduos, mesmo vivendo em um mesmo meio social. Em outras palavras: a unidade geracional constitui uma adesão mais concreta em relação àquela estabelecida pela conexão geracional. Mas a forma como grupos de uma mesma conexão geracional lidam com os fatos históricos vividos por sua geração (por exemplo, a ditadura militar no Brasil), fará surgir distintas unidades geracionais no âmbito da mesma conexão geracional. Por exemplo, em relação aos jovens paulistanos da década de 1970, Silva (2003) destaca que os mesmos se encontravam diante de pelo menos duas opções, as quais poderíamos exemplificar como duas unidades de geração:

Ela [a juventude] tinha como opções as manifestações finais e ingênuas do que foi a conhecida "jovem guarda", movimento musical brasileiro da metade final dos anos 1960, que teve como ícones os cantores Roberto Carlos, Wanderleia, Martinha, Erasmo Carlos, Jerry Adriani, entre outros, que imitava um pouco o estilo de um rock meloso, conhecido como iê-iê-iê, e no estilo de vestir soava rebelde, sem contudo chocar as famílias de classe média ... Outra opção era a 
cultura hippie que se espalhava nas grandes cidades, através do vestuário natural, colorido e despojado, dos longos cabelos para homens e mulheres, das bijuterias em profusão, da música pop e rock and roll, das drogas e da contracultura que, não necessariamente fazia parte do pacote (op. cit.: 44).

As unidades de geração podem ser vistas como o elemento que mais se aproxima dos grupos concretos. No entanto, o interesse de Mannheim não reside sobre o grupo, mas sobre "as tendências formativas e intenções primárias incorporadas, que, por sua vez, estabelecem um vínculo com as vontades coletivas" (p. 545). Nesse sentido, uma unidade de geração não é constituída por um grupo concreto, tampouco pelos conteúdos transmitidos através de expressões verbais ou corporais ou por meio de algum produto artístico produzido, por exemplo, por jovens pertencentes ao movimento hip-hop (cf. Weller, 2010). Uma unidade de geração se caracteriza pelas intenções primárias documentadas nas ações e expressões desses grupos. Essas intenções primárias ou tendências formativas só poderão ser analisadas a partir de um grupo concreto porque foram constituídas nesse contexto. Contudo, as intenções primárias não se reduzem ao grupo e aos atores, que, por sua vez, não se reduzem ao status de membros de um grupo concreto mas ao de atores coletivos envolvidos em um processo de constituição de gerações. A composição de gerações é, portanto, um processo sociogenético contínuo, no qual estão envolvidos, tanto grupos concretos, como a experiência adquirida em contextos comunicativos, entre outros, aqueles disponibilizados pelos meios de comunicação (cf. Schäffer, 2003: 66s).

Nesse sentido, o processo de constituição de gerações na perspectiva de Mannheim tampouco é algo específico das camadas altas intelectualizadas ou de grupos universitários como interpretado por Marialice Foracchi. Segundo a autora:

A análise de Mannheim sobre o problema das gerações apresenta algumas implicações que convêm explicitar. Preocupado em propor a noção de geração em moldes que não fôssem formais e estáticos, mas essencialmente históricos, êsse autor nivela, teòricamente, esta noção, à sua concepção de intelligentzia. Tal nivelamento teórico assenta sôbre alguns pressupostos básicos dos quais é possível destacar: $a$. os membros de uma geração jovem - pois é esta que se refere o autor - são os agentes humanos potenciais da intelligentzia; $b$. sua atuação no plano histórico e social reproduz a dimensão criativa da 
atuação da intelligentzia à qual, na concepção de Mannheim, cabe considerável parcela no processo de criação histórica e inovação cultural. Fica implícito, por conseguinte, que esta atuação de geração é mediatizada pela formação universitária, abrangendo tão-sòmente a parcela dos estratos sociais para os quais está socialmente assegurada tal possibilidade. Por outras palavras, compreende apenas a juventude das camadas altas e favorecidas. A busca de historicidade, no conceito, revelou-se comprometedora do seu rigor e da sua amplitude sistemática (1972: 22).

As forças mobilizadoras e constitutivas das referências históricas e culturais de uma geração independem de formação acadêmica, embora se reconheça a relevância e o papel desempenhado pelos movimentos estudantis na década de 1960. O funk e o hip-hop podem ser citados como exemplo de movimentos geracionais/juvenis não mediatizados pela formação acadêmica de seus precursores, os quais passaram a ocupar um espaço relevante no processo de constituição de gerações nos anos 1990, persistindo até o presente (cf. entre outros: Dayrell, 2005; Tavares, 2009; Weller, 2010).

Portanto, não seria procedente reduzir o processo constitutivo da geração 1968 ao universo do movimento estudantil, assim como os movimentos funk e hip-hop não são os únicos elementos formadores das gerações contemporâneas. Também seria incongruente e superficial afirmar, por um lado, que a enteléquia das novas gerações é constituída unicamente no âmbito dos movimentos estético-culturais mais destacados pelos meios de comunicação e, por outro, que as discussões travadas no âmbito das famílias, escolas ou universidades exercem pouca influência sobre as orientações coletivas das juventudes nesse início de século. Mannheim afirma sempre haver existido "polaridades" no âmbito das unidades geracionais, responsáveis pela mudança ou substituição dos polos dominantes entre um e outro período:

Nos anos 1930, não surgiu uma "nova geração" que de repente passou a ser novamente liberal-racionalista. Mas somente então a juventude que se encontrava na linha liberal-racionalista conseguiu chegar a uma reformulação geracional das tradições que a precediam. As polaridades básicas estavam por lá continuamente. Também existiu em todas as correntes, permanentemente, uma juventude; mas, a possibilidade de formação criativa dos impulsos geracionais, surgiu uma vez no polo romântico-conservador e, outra vez, no polo liberal-racionalista (p. 559). 
8. Estudos sobre juventudes com seus recortes específicos de gênero, raça/ etnia, vínculos regionais, religiosos, políticos, dentre outros, capazes de responder questões relativas às supostas diferenças entre as juventudes de décadas anteriores e os jovens de hoje praticamente inexistem. No entanto, observa-se que as pesquisas sobre juventude vem despertando interesse acadêmico sobretudo em forma de dissertações e teses (cf. Sposito, 2009; Weller, 2009).
Seria necessário ampliar os estudos comparativos sobre distintas gerações em um mesmo período cronológico assim como sobre gerações em tempos históricos distintos para uma melhor compreensão das polaridades existentes, bem como dos aspectos políticos, sociais e econômicos formadores dessas polaridades $^{8}$.

\section{4. À guisa de conclusão:}

Novas leituras sobre "O problema das gerações de Karl Mannheim" e a atualidade do conceito como categoria de análise

Como discutido anteriormente, Mannheim elabora na primeira parte do ensaio uma crítica ao positivismo francês, que explica as mudanças sociais com base no aspecto "biológico" e compreende geração como uma "variável capaz de flexibilizar e oferecer uma maior clareza às leis naturais que proporcionavam o progresso linear da humanidade" (Yncera, 1993: 148, trad. nossa). Ao mesmo tempo, apresenta a vertente histórico-romântica alemã, esforçando-se em buscar no problema geracional uma contraproposta à linearidade do fluxo temporal da história, para tanto, apoia-se em noções elaboradas por Dilthey e Pinder. Embora Mannheim não esconda sua preferência pela corrente histórico-romântica, também se distancia da mesma e acrescenta que o ponto de vista especificamente sociológico sobre o tema das gerações ainda não estava ao alcance do romantismo e do idealismo filosófico alemão.

Nesse sentido, suas análises sobre o problema das gerações não se situam no campo macro e tampouco microssociológico. Mannheim apresenta em seu ensaio sobre o problema das gerações uma proposta de superação da oposição existente entre objetivismo e subjetivismo. A necessidade de se construir uma "esfera intermediária" (pp. 232/554) de análise do problema, é apontada pelo autor como fundamental devido à insuficiência teóricometodológica constatada tanto no positivismo como no romantismo (cf. Yncera, op. cit.). Outros pesquisadores também destacam a "dimensão meso" presente na perspectiva mannheimiana, na qual os binarismos são superados na medida em que aponta para uma análise multidimensional das gerações. Mannheim compreende as gerações a partir de suas relações com o meio social (milieu), os sexos, a faixa etária, dentre outros (cf. Bohnsack \& Schäffer, 2002: 250-253 e Schäffer, 2003: 77-86). Tal perspectiva é ainda mais evidente quando uma geração passa a ser concebida não somente em distinção às outras gerações ou às posições geracionais - como sugerido por alguns estudiosos (cf. Bude, 2000) -, mas também em relação aos aspectos em co- 
mum existentes entre os membros de uma conexão geracional. Essa dimensão é elaborada com maior perspicácia nos trabalhos publicados somente a partir de 1980, nos quais Mannheim introduziu os espaços sociais de experiências conjuntivas (konjunktive Erfahrungsräume - cf. Weller, 2005) como elemento de análise.

Os atores acima citados chamam ainda a atenção para outro propósito presente no "problema das gerações". Por um lado, Mannheim atribui relevância sociológica à questão geracional:

Na alavancada da discussão sociológica do problema, Mannheim afirmou que o geracional constitui um problema importante, que precisa ser levado a sério, tendo em vista que se trata de "um guia indispensável para conhecer a estrutura dos movimentos sociais e espirituais". Com isso, o sentido concreto - a significação prática imediata - também adquire importância [...] ao tentar-se entender "a transformação acelerada dos fenômenos do presente" [...] tarefa concreta que Mannheim atribuiu à sociologia de seu tempo (Yncera, op. cit.: 157s).

Por outro, o estudo das gerações não se detêm apenas a um problema concreto, mas persegue um segundo interesse sociológico voltado para a busca de um método ou de um procedimento adequado para analisar a questão. $\mathrm{O}$ artigo discute um dos principais conceitos da sociologia do conhecimento de Mannheim e, ao mesmo tempo, apresenta o que essa corrente oferece em termos de produção teórica e metodológica (Bohnsack \& Schäffer, 2002: 251).

Nesse sentido, a atualidade deste artigo escrito em 1928 e do conceito de gerações desenvolvido pelo autor, recai, entre outros, sobre os seguintes aspectos:

1. O conceito de gerações de Mannheim e sua acurada elaboração sobre a posição, a conexão e a unidade geracional rompem com a ideia de uma unidade de geração concreta e coesa e nos instiga a centrar nossas análises nas intenções primárias documentadas nas ações e expressões de determinados grupos, ao invés de buscarmos caracterizar suas especificidades enquanto grupo. Perguntar-se pelos motivos das ações desses atores coletivos envolvidos em um processo de constituição de gerações, implica ainda em uma análise da conjuntura histórica, política e social a partir de uma perspectiva que po- 
deríamos situar no nível macro, bem como do conhecimento adquirido pelos atores nos espaços sociais de experiências conjuntivas, e que poderíamos denominar como sendo uma análise no campo micro.

2. A partir de uma questão concreta - o problema das gerações - Mannheim propõe um caminho teórico-metodológico a ser percorrido pelos pesquisadores, os quais não deveriam optar somente por uma ou outra corrente sociológica de análise, mas buscar esgotar as possibilidades de interpretação de um determinado tema. Em outro artigo - "Beiträge zur Theorie der Weltanschaungsinterpretation" (Contribuições para a teoria da interpretação das visões de mundo) - escrito originalmente entre 1921 e 1922, Mannheim apresenta um método voltado para a análise das visões de mundo e das experiências ateóricas desses atores, denominado método documentário de interpretação (cf. Weller et alii, 2002). Ao trazer como proposta metodológica a análise documentária dessas experiências ateóricas, o autor nos faz repensar o processo e o tratamento dado à interpretação sociológica (cf. Weller, 2005). Sendo assim, a atualidade da análise mannheimiana das gerações, reside, por um lado, na elaboração de uma perspectiva multidimensional de análise das relações sociais e geracionais. Por outro, Mannheim nos convida a repensar a construção de instrumentos analíticos capazes de mapear e dar forma à singularidade de experiências concretas, que carecem de uma análise teórica. Em outras palavras, sua perspectiva não representa apenas uma contribuição teórica para os estudos sobre gerações, mas também uma proposta teórico-metodológica de pesquisa, capaz de superar as dimensões binárias presentes em algumas correntes teórico-metodológicas.

Abstract: The concept of generations has been incorporated into sociological analysis, which points class differences but also gender, ethnic, racial, cultural and generational inequalities. However "generations" seems to be a kind of umbrella concept or category that have been little theorized. Though the concept of generations of Mannheim represent, for many authors, the most comprehensive attempt to explain the issue, it has been frequently quoted since it is a "classic". The possibilities of analysis of the concept proposed by the author still are many. This article presents, first, a reconstruction of this 'famous' essay which has not yet come to be fully translated and published in Brazil, and secondly, discusses the relevance and appropriateness of the article written by Mannheim in 1928 for the contemporary studies of generation and their interfaces with other fields.

Key words: generation, sociology of knowledge, Karl Mannheim. 


\section{Bibliografia}

BoHnsaCK, Ralf \& SCHÄFFER, Burkhard (2002). "Generation als konjunktiver Erfahrungsraum. Eine empirische Analyse generationsspezifischer Medienpraxiskulturen", in Günter Burkart \& Jürgen Wolf (orgs), Lebenszeiten. Erkundungen zur Soziologie der Generationen, Opladen: Leske \& Budrich, pp. 249-273.

BudE, Heinz (2000). "Die biographische Relevanz der Generation”, in Martin Kohli \& Marc Szydlik (orgs), Generationen in Familie und Gesellschaft, Opladen: Leske \& Budrich, pp. 19-35.

Breitsamer, Joachim (1976). "Ein Versuch zum 'Problem der Generationen'”, Kölner Zeitschrift für Soziologie und Sozialpsychologie (KZfSS), Ano 28, n. 3, pp. 451-478.

DaYReLL, Juarez (2005). A música entra em cena: O rap e o funk na socialização da juventude, Belo Horizonte: Editora UFMG.

Domingues, José Maurício (2002). "Gerações, modernidade e subjetividade coletiva", Tempo Social, São Paulo, Vol. 14, n. 1, pp. 67-89.

Fernandes, Florestan (1970). "A concepção de ciência política de Karl Mannheim", in idem, Elementos de sociologia teórica, São Paulo: Cia Editora Nacional/Edusp, pp. 223-291.

FoRACCHI, Marialice M. (1972). A juventude na sociedade moderna, São Paulo: Pioneira.

Forquin, Jean-Claude (2003). "Relações entre gerações e processos educativos: Transmissões e transformações", comunicação apresentada no Congresso Internacional Co-Educação de Gerações, São Paulo, SESC, outubro de 2003. Disponível em: http://www.sescsp.org.br/sesc/images/ upload/conferencias/83.rtf [acesso em 22/06/2005].

Hofmann,Wilhelm (1996). Karl Mannheim: Zur Einführung, Hamburg: Junius.

KetrleR, David (1989). Karl Mannheim [por David Kettler, Volker Meja, Nico Stehr], Mexico: Fondo de Cultura Economica. 
Mannheim, Karl (1964). "Das Problem der Generationen", in idem, Wissenssoziologie [introdução e organização: Kurt H. Wolff], Neuwied: Luchterhand, pp. 509-565.

- (1952). "The problem of Generations", in idem, Essays on the Sociology of Knowledge [introdução e organização: Paul Kecskemeti]. Londres: Routledge \& Kegan Paul, pp. 276-322.

- (1993). "El problema de las generaciones" [tradução: Ignacio Sánchez de la Yncera], Revista Española de Investigaciones Sociológicas (REIS), n. 62, pP. 193-242.

— (1982). "O problema sociológico das gerações" [tradução: Cláudio Marcondes], In Marialice M. Foracchi (org), Karl Mannheim: Sociologia, São Paulo, Ática, pp. 67-95.

- (s/d). "O problema das gerações" [tradução: Maria da Graça Barbedo], in idem, Sociologia do conhecimento, Vol. II, Porto, RES-Editora, pp. 115176, [1928].

- (1961). "O problema da juventude na sociedade moderna", in idem, Diagnóstico de nosso tempo, Rio de Janeiro: Zahar, pp. 36-61.

— (1980). Strukturen des Denkens, Frankfurt/M.: Suhrkamp.

- (1982). Structures of thinking, Collected Works, Vol. X, Londres: Routledge \& Kegan Paul.

- (2001). “O problema da 'intelligentsia': Um estudo de seu papel no passado e no presente", in idem, Sociologia da cultura, 2. ed., São Paulo: Perspectiva, pp. 69-139.

Matthes, Joachim (1985). "Karl Mannheims 'Das Problem der Generationen', neu gelesen", Zeitschrift für Soziologie, Ano 14, n. 5, pp. 363-372.

Ros, Salvador Cardús I. (1993). "Notas para uma lectura actualizada de 'Ideologia y utopía'", Revista española de investigaciónes sociológicas (REIS), n. 62, pp. 123-132.

SCHÄFFER, Burkhard (2003). Generationen - Medien - Bildung: Medienpraxiskulturen im Generationenvergleich, Opladen: Leske \& Budrich. 
SILvA, Elisabeth M. (2003). "A violência diletante: Um estudo sobre as brigas juvenis no contexto do lazer", tese de doutorado em ciências sociais, São Paulo: PUC.

Sparschuh, Vera (2000). "Der Generationsauftrag - bewusstes Erbe oder 'implizites Wissen'?: Karl Mannheims Aufsatz zum Problem der Generationen im Kontext seines Lebenswerkes", Sociologia Internationalis, Vol. 38, n. 2, pp. 219-243.

Sposıto, Marília (2009). O Estado da arte sobre juventude na pós-graduação brasileira: Educação, ciências sociais e serviço social (1999-2006), Belo Horizonte: Argumentum.

TAVARES, Breitner L. (2009). “Na quebrada a parceria é mais forte - juventude hip-hop: Relacionamento e estratégias contra a discriminação na periferia do Distrito Federal", tese de doutorado em sociologia, Brasília: UnB.

YNCERA, Ignacio Sánchez de la (1993). “Crisis y orientación. Apuntes sobre el pensamiento de Karl Mannheim", Revista Española de Investigaciones Sociológicas (REIS), n. 62, pp. 17-43.

- (1993). "La sociología ante el problema generacional. Anotaciones al trabajo de Karl Mannheim", Revista Española de Investigaciones Sociológicas (REIS), n. 62, pp. 147-192.

— (1993). "La obra de Karl Mannheim. Una compilación actualizada de sus escritos más relevantes", Revista Española de Investigaciones Sociológicas (REIS), n. 62, pp. 245-253.

Weller, Wivian et alii (2002). "Karl Mannheim e o método documentário de interpretação: Uma forma de análise das visões de mundo", Sociedade $e$ Estado, Vol. 17, n. 2, "Inovações no campo da metodologia das ciências sociais", pp. 375-396.

(2005). "A contribuição de Karl Mannheim para a pesquisa qualitativa: Aspectos teóricos e metodológicos", Sociologias, Vol. 7, n. 13, pp. 260-300.

- (2007). "Karl Mannheim: Um pioneiro da Sociologia da Juventude", paper apresentado no XIII Congresso Brasileiro de Sociologia, Recife [Disponível em: http:// www.sbsociologia.com.br/congresso_v02/papers/ gt 26\%20sociologia\%20da\%20inf\%c3\%a2ncia\%20e\%20juventude/ gt26_sbs2007_paper_wivianweller_vf\%5b1\%5d.pdf]. 
- (2007). "Juventude e diversidade: Articulando gênero, raça e sexualidade", Anais do Colóquio Luso-Brasileiro de Sociologia da Educação [CD-R], Belo Horizonte, Faculdade de Educação, UFMG, 2008, pp. 1-16.

- (2010). Minha voz é tudo o que eu tenho: Manifestações culturais em Berlim e São Paulo, Belo Horizonte: Editora UFMG.

ZINNECKER, Jürgen (2002). "Das Deutungsmuster Jugendgeneration. Fragen an Karl Mannheim", in H. Merkens \& J. Zinnecker (orgs), Jahrbuch Jugendforschung, n. 2/2002, Opladen, pp. 61-99. 